\title{
Effect of enucleation of the corpus luteum at different stages of the luteal phase of the human menstrual cycle on subsequent follicular development
}

\author{
D. T. Baird, T. Bäckström, A. S. McNeilly, S. K. Smith and C. G. Wathen \\ Department of Obstetrics \& Gynaecology \& M.R.C. Reproductive Biology Unit, \\ Centre for Reproductive Biology, 37 Chalmers Street, Edinburgh EH3 9EW, U.K.
}

\begin{abstract}
Summary. To investigate the mechanism of suppression of follicular development during the luteal phase of the human menstrual cycle, the corpus luteum was enucleated surgically from 10 women at various times after ovulation. In the $24 \mathrm{~h}$ after CL enucleation there was an immediate and rapid fall in the concentration of oestradiol and progesterone and a temporary decline in the concentration of FSH and LH. Within 3 days, however, all 10 women showed evidence of renewed follicular activity as indicated by a progressive rise in the concentration of oestradiol. This rise was preceded by a rise in the concentration of FSH and LH, and ovulation, as indicated by a mid-cycle surge in LH and rise in the concentration of plasma progesterone, occurred 16-19 days after enucleation. There was no significant difference in the time to ovulation following enucleation at different times of the luteal phase. The postoperative follicular phase, measured from the time of enucleation, was 3 days longer than that observed pre-operatively from the first day of menstrual bleeding. In the follicular phase of post-operative cycles the concentration of FSH was higher and that of oestradiol lower than the corresponding values before surgery.

These results indicate that the absence of healthy antral follicles in the luteal phase of the cycle is due to the inhibitory effects of the corpus luteum. The fact that, after CL enucleation, emergence of the dominant follicle was always preceded by a rise in the concentration of FSH and LH suggests that suppression of gonadotrophins by ovarian steroids secreted by the corpus luteum is responsible for the inhibition of follicular development during the luteal phase of the cycle.
\end{abstract}

\section{Introduction}

During the luteal phase of the menstrual cycle in the human and the rhesus monkey all large antral follicles ( $>4 \mathrm{~mm}$ diameter) are atretic (Block, 1951; Koering, 1969; McNatty et al., 1983). It has been suggested that this inhibition of follicular development in the primate is due to suppression of gonadotrophin levels by the combined negative feedback effect of oestradiol and progesterone secreted by the corpus luteum (Baird, Baker, McNatty \& Neal, 1975). Removal of the corpus luteum by surgical enucleation during the luteal phase in rhesus monkeys and in women results in restoration of follicular development and ovulation occurs 12-14 days later (Goodman, Nixon, Johnson \& Hodgen, 1977; Nilsson, Wikland \& Hamberger, 1982). This effect can be delayed by administration of progesterone, suggesting that this steroid normally plays a key role in inhibiting follicular development during the luteal phase (di Zerega \& Hodgen, 1981). 
The factors initiating development of antral follicles and subsequent selection of the dominant follicle are complex and not fully understood (Baird \& McNeilly, 1981; Hodgen, 1982). It has been suggested that the rise in FSH which occurs coincidentally to the mid-cycle LH surge in the rat is important in recruiting follicles of the next cycle (Schwartz, 1974). However, in the primate it is likely that the rise in FSH (and LH) that occurs towards the end of the cycle as the corpus luteum regresses plays a critical role in stimulating the development of the small antral follicle which will eventually ovulate (McNatty, 1982; Baird, 1983). Goodman et al. (1977) were unable to detect any change in the concentration of FSH or $\mathrm{LH}$ following enucleation of the corpus luteum in rhesus monkeys and Goodman \& Hodgen (1977) concluded that progesterone has a direct inhibitory effect on follicle growth in the ovary.

In the present experiments we have measured the changes in the concentration of steroids and gonadotrophins before and after surgical enucleation of the corpus luteum at the time of hysterectomy in 10 women.

\section{Materials and Methods}

\section{Subjects}

Ten women scheduled for hysterectomy because of heavy periods and/or fibroids were recruited from the Gynaecological Out-Patient Department of the Royal Infirmary, Edinburgh. Written informed consent was obtained from all patients before admission to the study. The mean age was 38 years (range 32-44 years) and the mean menstrual length varied between $25 \pm 2$ and $27 \pm 3$ days.

On the morning of operation a blood sample was collected before premedication with $0.6 \mathrm{mg}$ atropine and $5 \mathrm{mg}$ diamorphine. Bupivacaine hydrochloride (0.5\% Marcain: Duncan, Flockart \& Co., London) was injected into the epidural space and general anaesthesia induced by thiopentone and maintained with a mixture of nitrous oxide and oxygen. After opening of the abdominal cavity the corpus luteum was enucleated by a combination of sharp and blunt dissection. Bleeding from the enucleation site was easily controlled by one or two mattress sutures of $3 / 0$ polypropylene (Prolene: Ethicon Ltd, Edinburgh) and the ovarian capsule reconstructed with a continuous suture of the same material. After the operation the patients received on average $52 \mathrm{mg}$ diamorphine (range 30-70 $\mathrm{mg}$ ) for approximately $48 \mathrm{~h}$ (ranges 45-52 h).

Daily blood samples were collected from all 10 patients for at least 2 days before and 14 days after hysterectomy. In those subjects for whom daily blood samples were available at the appropriate time ovulation was assumed to occur on the day after mid-cycle LH peak (Djahanbakhch, McNeilly, Hobson \& Templeton, 1981). In the remainder, in whom only urinary total oestrogen and pregnanediol excretion were available, ovulation was assumed to occur on the day when the urinary excretion of pregnanediol rose at least 2-fold above the level found during the follicular phase. In 7 patients in whom daily blood samples were begun by Day 5 of the cycle before admission to hospital, it was possible to date the time of hysterectomy in relation to the mid-cycle LH surge. In the remaining 3 patients, blood sampling was not begun until admission to hospital, 2 days before surgery and the time of the luteal phase was based on the rise of the urinary excretion of pregnanediol and the histology of the endometrium. Of these 3 women, 2 were operated on within 4 days of ovulation (early luteal, EL) and the remaining woman during the late luteal phase ( $>10$ days after ovulation, LL). In these women it was not possible to calculate the length of the follicular phase exactly because a sample was not collected on the day of the LH surge. Hence a range representing the extremes within which ovulation must have occurred was calculated. In the 3 women in whom the corpus luteum was enucleated between Days 4 and 10 (mid-luteal, ML) the day of the LH surge was identified and hence no range is given.

A complete series of daily blood samples extending to the day of the post-operative mid-cycle LH surge was available for 6 women. Urine was also collected from 1 woman every day after 
cessation of blood samples for the measurement of total oestrogen and pregnanediol. In the remaining 3 patients ovulation occurred between Day 14 after operation, when the daily blood sampling was stopped, and Day 21 when the concentration of progesterone was found to be $>5$ $\mathrm{ng} / \mathrm{ml}$.

Blood samples were collected from 6 women immediately before and 4, 8, 12, 24, 48 and $72 \mathrm{~h}$ after operation to study the acute effects of CL enucleation and operation on levels of gonadotrophins and steroids.

\section{Hormone assays}

Oestradiol and progesterone were measured after extraction of the plasma with diethyl ether (Scaramuzzi, Corker, Young \& Baird, 1975; Van Look, Lothian, Hunter, Michie \& Baird, 1977). The intra- and inter-assay precision were 8 and $12 \%$ for both assays and the sensitivities were 5 and $140 \mathrm{pg} / \mathrm{ml}$ for oestradiol and progesterone respectively. FSH and LH were assayed using a doubleantibody radioimmunoassay (Hunter \& Bennie, 1979; Vaughan-Williams, McNeilly \& Baird, 1982). The antisera which were raised in rabbits against human FSH (m93) and LH (F87) were kindly supplied by Dr S. Lynch. The results were expressed as units/litre in terms of standards obtained from the National Institute of Biological Standards and Control, Holly Hill, London (LH: 68/40, 77 units per ampoule; FSH 69/104, 10 units per ampoule). The intra- and inter-assay coefficients of variation were 10 and $12 \%$ for both assays and the sensitivities were 0.2 and 0.1 $\mathrm{mu} / \mathrm{ml}$ for $\mathbf{L H}$ and FSH respectively.

Total oestrogen in urine was measured by a semi-automatic fluorometric technique (Brown, MacLeod, Macnaughton, Smith \& Smyth, 1968) and pregnanediol by gas-liquid chromatography (Chamberlain \& Contractor, 1968). The coefficients of variation in the range of samples measured were 11 and $12 \%$ and the sensitivities were $0.5 \mu \mathrm{g} / 24 \mathrm{~h}$ and $0.2 \mathrm{mg} / 24 \mathrm{~h}$ for oestrogen and pregnanediol respectively.

\section{Statistical evaluation}

A $\log$ normal distribution was assumed and all data were log transformed before statistical evaluation. Non-parametric statistics were used to test differences between two single means (Siegel, 1956). When the means from more than two groups were to be tested, one-way analysis of variance was used. Two-way analysis of variance was used to test differences between groups over several days (Wonnacolt \& Wonnacolt, 1972).

\section{Results}

\section{Follicular-phase length after enucleation of $C L$}

Following enucleation of the CL all 10 women showed evidence of renewed follicle activity and ovulated within 16-19 days (Text-figs $1 \& 2$ ). There was no significant difference between time to ovulation after enucleation at different stages of the luteal phase (Table 1). In the EL and LL groups a sample was not collected on the day of the LH surge in every subject and hence a maximum and minimum value was calculated in each group. All four combinations of maximum and minimum length in the EL and LL groups were not significantly different from those of the ML group when tested by one-way analysis of variance. The values for all three stages of the luteal phase were therefore combined in subsequent analyses.

For one woman no measurements were available pre-operatively to date ovulation precisely. For the remaining 9 women the mean post-operative follicular phase measured from the time of enucleation of the corpus luteum was approximately 3 days longer than that observed before operation taken from the first day of menstrual bleeding $(P<0 \cdot 01$, Wilcoxon matched-pair signrank test, see Table 1 ). 
Table 1. The length of the follicular phase after removal of the corpus luteum in women $(\mathrm{N})$ at different stages of the luteal phase, and comparison before and after operation

\begin{tabular}{llcr}
\hline \multicolumn{2}{l}{ Stage of luteal phase } & $\begin{array}{c}\text { Mean length } \pm \text { s.e. } \\
\text { (days) }\end{array}$ & N \\
\hline Early (EL) & Min. & $15 \cdot 3 \pm 0 \cdot 25^{\mathrm{a}}$ & 4 \\
& Max. & $20 \cdot 5 \pm 1 \cdot 5^{\mathrm{a}}$ & \\
Middle (ML) & & $18 \cdot 3 \pm 1 \cdot 2^{\mathrm{a}}$ & 3 \\
Late (LL) & Min. & $17 \cdot 0 \pm 1 \cdot 5^{\mathrm{a}}$ & 3 \\
& Max. & $18 \cdot 0 \pm 2 \cdot \cdot^{\mathrm{a}}$ & \\
Pre-operative & Min. & $14 \cdot 0 \pm 0 \cdot 8^{\mathrm{b}}$ & 9 \\
& Max. & $14 \cdot 1 \pm 0.8^{\mathrm{b}}$ & \\
Post-operative & Min. & $16 \cdot 6 \pm 0 \cdot 7^{\mathrm{b}}$ & 9 \\
& Max. & $18 \cdot 9 \pm 1 \cdot 0^{\mathrm{b}}$ & \\
\hline
\end{tabular}

a No significant difference between any of these values (one-way ANOVA).

${ }^{b} P<0.01$ (Wilcoxon matched-pair sign test for preand post-operative values).

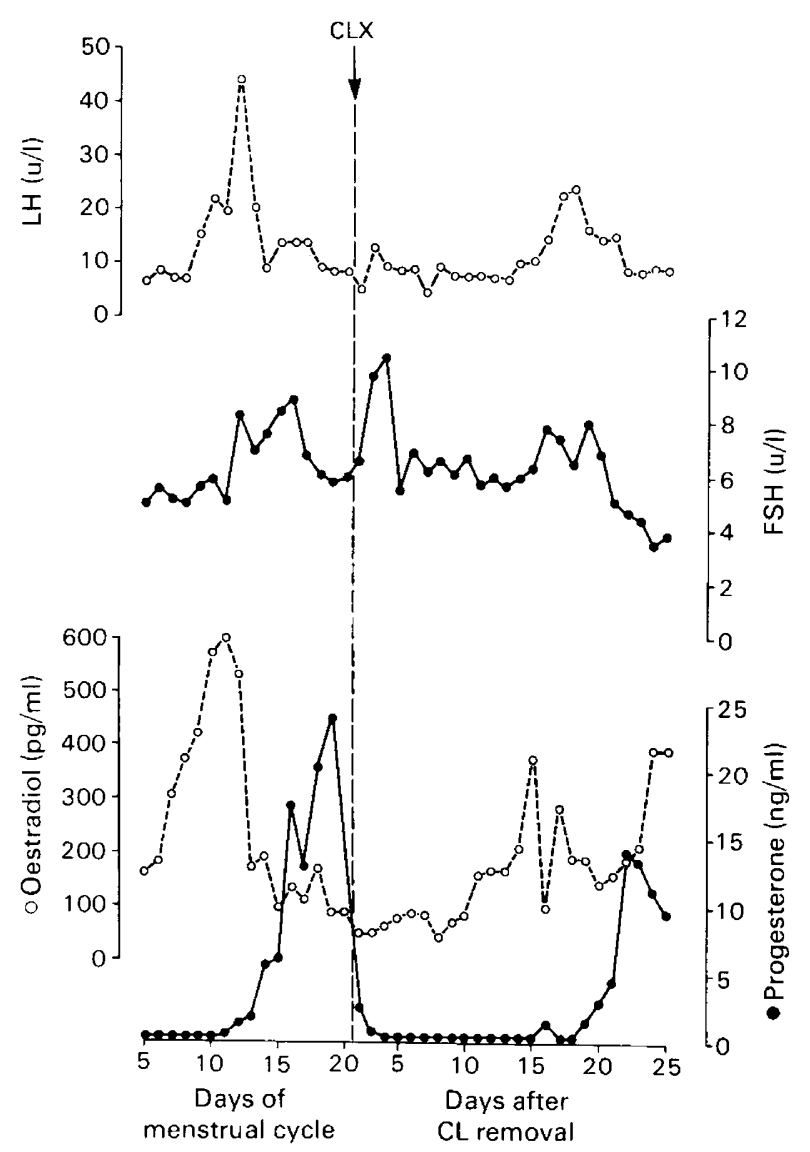

Text-fig. 1. The concentrations of LH, FSH, oestradiol and progesterone in plasma of an individual patient before and after enucleation of the corpus luteum (CLX). 


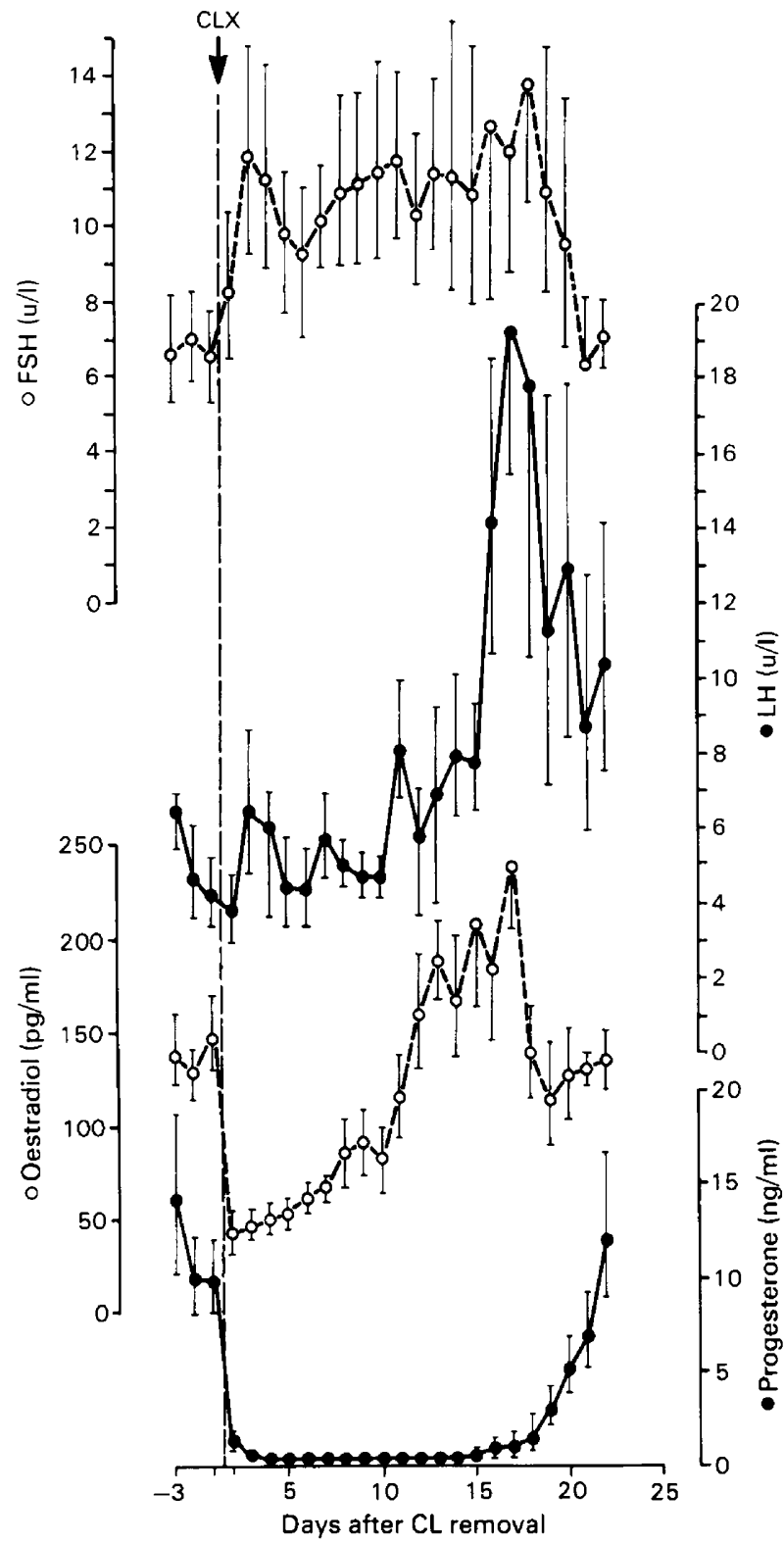

Text-fig. 2. The mean \pm s.e.m. concentrations of gonadotrophins and ovarian steroids before and after enucleation of the corpus luteum (CLX). The data were log transformed before analysis $(\mathbf{N}=10)$.

\section{Hormone change following enucleation of $C L$}

There was an immediate fall in the concentration of oestradiol and progesterone after CL enucleation (Text-figs $1 \& 2$ ). Over the next 14 days the concentration of oestradiol rose progressively to reach peak value 18 days after enucleation.

The concentration of both FSH and LH both fell significantly in the $24 \mathrm{~h}$ following operation (Text-fig. 3). The concentration of LH returned to the pre-operative value by $12 \mathrm{~h}$ and rose gradually over the next 10 days. The concentration of FSH remained significantly lower than the 
pre-operative value for $24 \mathrm{~h}$ but thereafter rose progressively (Text-fig. 2). The FSH concentration 1 week after $C L$ enucleation was significantly higher than the mean levels in the 3 days before operation $(\mathrm{F}(1,85)=8.31, P<0.005$, one-way analysis of variance $)$.

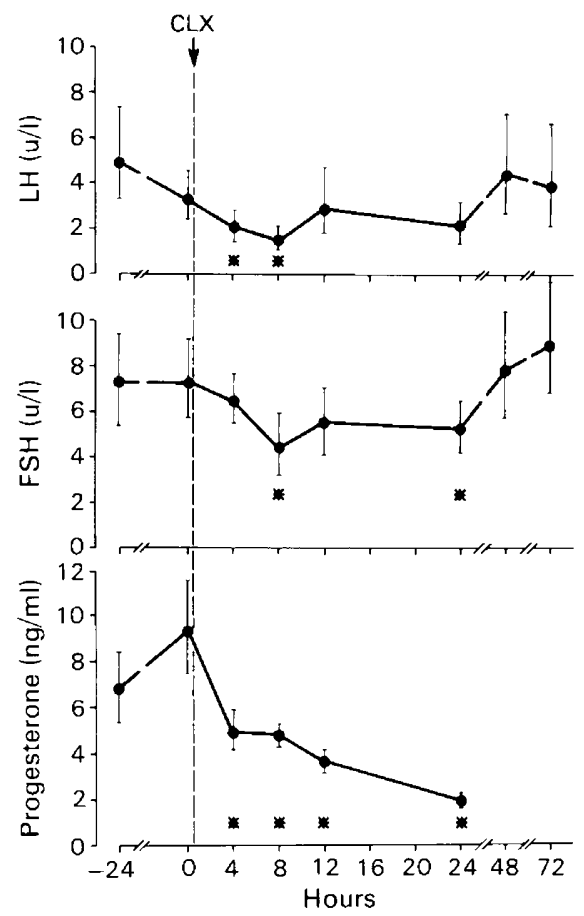

Text-fig. 3. The mean \pm s.e.m. concentrations of LH, FSH and progesterone in the perioperative period. The data were log transformed before analysis. *Statistically significantly different from pre-operative value $(P<0.05$, Wilcoxon matched-pair sign test $)(\mathrm{N}=6)$.

About 17 days after enucleation there was a marked rise in the concentration of $\mathrm{LH}$ associated with a smaller rise in FSH level. Following this surge the concentration of progesterone rose progressively.

To compare the levels of hormones in the pre-and post-operative cycles the values were centred around the mid-cycle LH peak. The FSH concentration in the 5 days before the LH peak was significantly higher post-operatively than pre-operatively in the same subjects $(\mathrm{F}(1,10)=13 \cdot 4, P<$ 0.005 , two-way analysis of variance; see Text-fig. 4). There were no significant differences in the concentration of $\mathrm{LH}$ but the concentration of oestradiol during the last 5 days of the follicular phase was significantly lower post-operatively $(\mathrm{F}(1,10)=17 \cdot 2, P<0.005$, two-way analysis of variance). Although most values were within the normal range, the post-operative oestradiol peak was significantly lower than the corresponding value pre-operatively $(252 \pm 50$ compared with $420 \pm$ $71 \mathrm{pg} / \mathrm{ml}: \mathrm{F}(1,5)=13.9, P<0.025$, two-way analysis of variance).

After the LH peak, the rise in concentration of progesterone was significantly lower postoperatively than were the pre-operative values $(\mathrm{F}(1,4)=12.5, P<0.025$, two-way analysis of variance).

\section{Discussion}

The results of the present study confirm two previous reports in which the concentration of oestradiol and progesterone fell to very low levels following surgical removal of the corpus luteum 


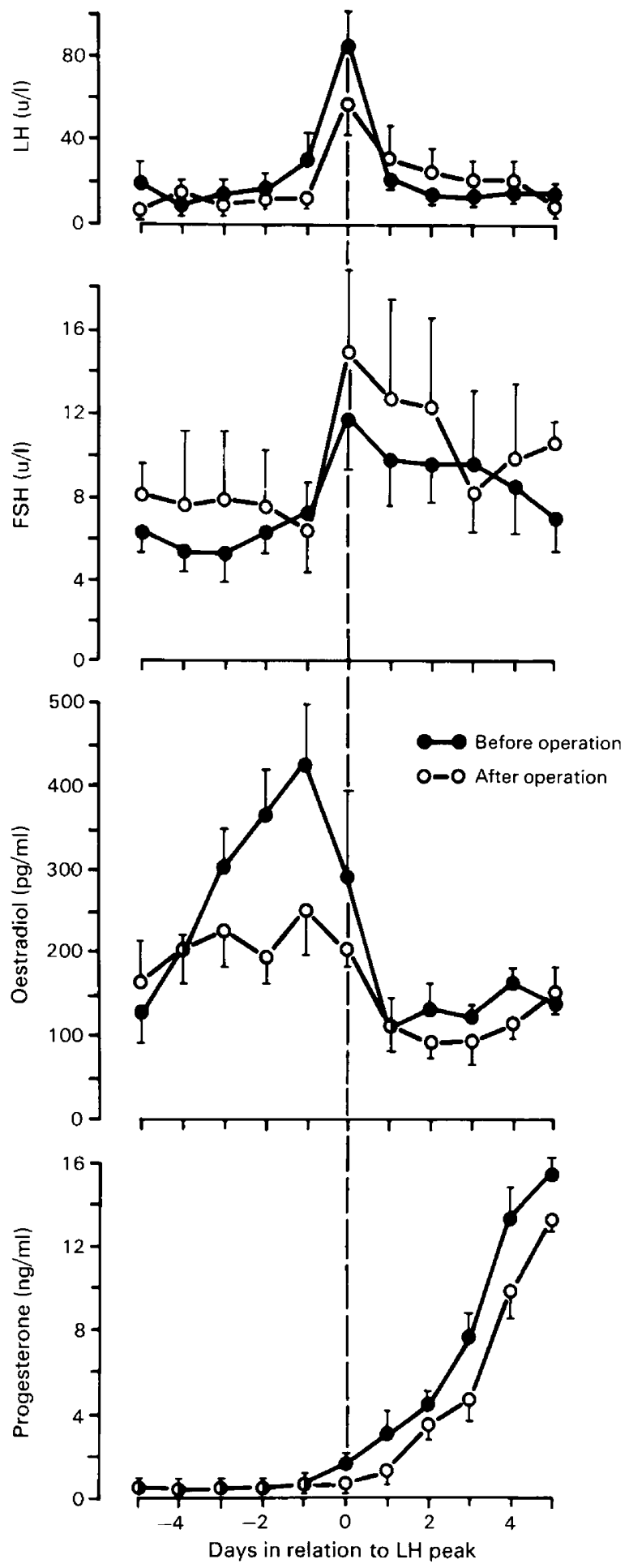

Text-fig. 4. Mean \pm s.e.m. concentrations of $\mathrm{LH}, \mathrm{FSH}$, oestradiol and progesterone pre- and post-operatively. The data have been centred round the day of the $\mathrm{LH}$ peaks and hence the absolute values for the peak differ from those in Text-fig. $2(\mathrm{~N}=6)$. 
(Aedo, Pedersen, Pedersen \& Diczfalusy, 1980; Nilsson et al., 1982). These results, together with the high concentration of these steroids in the CL (Swanston, McNatty \& Baird, 1977) and in ovarian venous blood (Mikhail, 1970; Lloyd et al., 1971; Baird, 1977; Aedo et al., 1980), are conclusive proof that the $\mathrm{CL}$ is the major source of oestradiol and progesterone in the luteal phase of the human menstrual cycle.

The suppression of FSH and LH for 12-24 h after operation was probably due to the effect of general anaesthesia and post-operative sedation (Charters, Odell \& Thompson, 1969; Carstensen, Amer, Wide \& Amer, 1973; Yen, Vandenberg, Tsai \& Parker, 1974). In the $48 \mathrm{~h}$ following operation the women received on average $52 \mathrm{mg}$ diamorphine which is known to suppress LH and FSH secretion (Meites, Bruni, Van Vugt \& Smith, 1979). Thereafter the concentration of both gonadotrophins rose above the pre-operative values, in a manner similar to that observed during spontaneous regression of the corpus luteum in the late luteal phase of the cycle. These results are in keeping with the suggestion that the low concentrations of gonadotrophins which are found during the luteal phase are due to the negative feedback effect of both oestradiol and progesterone (Faiman \& Ryan, 1967; Midgley \& Jaffe, 1968; Baird et al., 1975).

During the luteal phase of the cycle there is a marked change in follicular activity in women (Block, 1951; Gougeon, 1982) and rhesus monkeys (Koering, 1969). Virtually all antral follicles of diameter greater than $4 \mathrm{~mm}$ are in various stages of atresia (McNatty et al., 1983). The present result confirms previous studies on monkeys (di Zerega \& Hodgen, 1981) and women (Nilsson et al., 1982) that follicular growth and ovulation recommence following enucleation of the corpus luteum. The fact that the time to ovulation was similar following enucleation in the early, mid- and late luteal phase indicated that there are no defined 'waves' of follicular activity during the luteal phase. Therefore, if the mid-cycle peak of FSH stimulates follicular activity it must have an effect on follicles of diameter $<2-4 \mathrm{~mm}$.

The post-operative follicular phase was approximately 3 days longer than that observed preoperatively (Table 1). The latter was measured from the time of onset of menstrual bleeding which is approximately 2 days after the onset of luteal regression and coincides with a rise in the concentration of FSH and LH (Ross et al., 1970). This rise in the concentration of gonadotrophins was delayed by $24 \mathrm{~h}$ following surgery (Text-fig. 3). Thus the time from the gonadotrophin rise to the LH peak observed after enucleation ( 14 days) is similar to the corresponding interval in normal women.

Although all women showed evidence of ovulation post-operatively, as indicated by the surge of $\mathrm{LH}$ and subsequent rise in the concentration of progesterone, there were certain differences in the pattern of hormones in the post-operative cycle. The concentration of FSH was significantly higher in the follicular phase of the post-operative than of the pre-operative cycle (Text-fig. 4). It may be that the reduced levels of FSH which occurred in the $24 \mathrm{~h}$ after surgery resulted in a sub-optimal priming of the early antral follicle with consequent reduced secretion of oestradiol and possibly inhibin (Strott, Cargille, Ross \& Lipsett, 1970; di Zerega \& Hodgen, 1981). The relatively slow rise in progesterone concentration after ovulation would be in keeping with a degree of 'inadequate corpus luteum' (Lenton, Adams \& Cooke, 1978).

However, in contrast to the studies with rhesus monkeys, in our study follicular development, as indicated by a progressive rise in the concentration of oestradiol, was always preceded by a rise in the concentration of FSH and LH. Di Zerega \& Hodgen (1981) suggested that follicular development may have been inhibited by the local effect of progesterone on the adjacent ovarian tissue. However, it is difficult to resolve this view with the fact that ovulation can occur in either ovary irrespective of the presence of a CL (Clark, Dierschke \& Wolf, 1978). The failure to detect a change in the basal values of FSH or LH following removal of the CL may be due to the limitations of the present radioimmunoassays for gonadotrophins in the rhesus monkey since there are marked discrepancies between the values obtained with radioimmunoassay and bioassay in this species (Marut et al., 1981). 
We are grateful to Mr K. A. Swanston for technical assistance, to Mrs A. Cook and Mrs J. Gray for help in collecting the blood samples and to Dr W. Hunter for the assay of LH and FSH in some of the samples. T.B. was supported by a Wellcome Trust Research Grant.

\section{References}

Aedo, A.R., Pedersen, P.H., Pedersen, S.C. \& Dictfalusy, E. (1980) Ovarian steroid secretion in normally menstruating women. II. The contribution of the corpus luteum. Acta endocr., Copenh. 95, 222-231.

Baird, D.T. (1977) Content and secretion of steroids by the human ovary in vivo. In Endocrinology, Vol. I, pp. 330-336. Ed. V. H. T. James. Excerpta Medica, Amsterdam.

Baird, D.T. (1983) Factors regulating the growth of the pre-ovulatory follicle in the sheep and human. $J$. Reprod. Fert. 69, 343-352.

Baird, D.T. \& MeNeilly, A.S. (1981) Gonadotrophic control of follicular development and function during the oestrous cycle of the ewe. J. Reprod. Fert., Suppl. 30, 119-133.

Baird, D.T., Baker, T.G., McNatty, K.P. \& Neal, P. (1975) Relationship between the secretion of the corpus luteum and the length of the follicular phase of the ovarian cycle. J. Reprod. Fert. 45, 611-619.

Block, E. (1951) Quantitative morphological investigation of the follicular system in women. Acta endocr., Copenh. 8, 33-54.

Brown, J.B., MacLeod, S.C., Macnaughton, C., Smith, M.A. \& Smyth, B. (1968) A rapid method for estimating oestrogens in urine using a semi-autematic extractor. J. Endocr. 42, 5-16.

Carstensen, H., Amer, I., Wide, L. \& Amer, B. (1973) Plasma testosterone, $\mathrm{LH}$ and FSH during the first 24 hours after surgical operations. J. Steroid Biochem. 4, 605-611.

Chamberlain, J. \& Contractor, S.F. (1968) A gas-liquid chromatographic method for the rapid estimation of pregnanediol and allopregnanediol in non-pregnancy urine. Am. J. Obstet. Gynec. 101, 649-657.

Charters, A.C., Odell, W.D. \& Thompson, J.C. (1969) Anterior pituitary function during surgical stress and convalescence. Radioimmunoassay measurement of blood TSH, LH, FSH and growth hormone. J. clin. Endocr. Metab. 29, 63-71.

Clark, J.R., Dierschke, D.J. \& Wolf, R.C. (1978) Hormonal regulation of ovarian folliculogenesis in rhesus monkeys. 1. Concentrations of serum luteinizing hormone and progesterone during laparoscopy and patterns of follicle development during successive menstrual cycles. Biol. Reprod. 18, 779-783.

di Zerega, G.S. \& Hodgen, G.D. (1981) Folliculogenesis in the primate ovarian cycle. Endocr. Rev. 2, 27-49.

Djahanbakhch, O., McNeilly, A.S., Hobson, B.M. \& Templeton, A.A. (1981) A rapid luteinizing hormone radioimmunoassay for the prediction of ovulation. Br. J. Obstet. Gynaec. 88, 1016-1020.

Faiman, C. \& Ryan, R.J. (1967) Serum follicle-stimulating hormone and luteinizing hormone concentrations during the menstrual cycle as determined by radioimmunoassays. J. clin. Endocr. Metab. 27, 1711-1716.
Goodman, A.L. \& Hodgen, G.D. (1977) Systemic versus intra-ovarian progesterone replacement after luteectomy in rhesus monkeys: differential patterns of gonadotrophins and follicle growth. J. clin. Endocr. Metab. 45, 837-840.

Goodman, A.L., Nixon, N.B., Johnson, D.K. \& Hodgen, G.D. (1977) Regulation of folliculogenesis in the cycling rhesus monkey: selection of the dominant follicle. Endocrinology 100, 155-161.

Gougeon, A. (1982) Rate of follicular growth in the human ovary. In Follicular Maturation and Ovulation, pp. 155-163. Eds. R. Rolland, E. V. van Hall, S. G. Hillier, K. P. McNatty \& J. Schoemaker. Excerpta Medica, Amsterdam.

Hodgen, G.D. (1982) Selection and ovulation of the dominant follicle: role of intra-ovarian progesterone. In Hormonal Factors in Fertility, Infertility and Contraception, pp. 28-44. Eds H. J. van der Molen, A. Klopper, B. Lunenfeld, M. Neves e Castro, F. Sciarra \& A. Vermeulen. Excerpta Medica (ICS No. 580), Amsterdam.

Hunter, W.M. \& Bennie, J.C. (1979) Reduction of nonspecific serum responses in human pituitary gonadotrophin radioimmunoassay. $J$. Endocr. 80, 59-68.

Koering, M.J. (1969) Cyclic changes in ovarian morphology during the menstrual cycle in Macaca mulatta. Am. J. Anat. 126, 73-101.

Lenton, E.A., Adams, M. \& Cooke, I.D. (1978) Plasma steroid and gonadotrophin profiles in ovulatory but infertile women. Clin. Endocr. 8, 241-255.

Lloyd, C.W., Lobotsky, J., Baird, D.T., McCracken, J.A., Weisz, J., Pupkin, M., Zanartu, J. \& Puga, J. (1971) Concentration of unconjugated estrogens, androgens and gestogens in ovarian and peripheral venous plasma of women: the normal menstrual cycle. J.clin. Endocr. Metab. 32, 155-166.

Marut, E.L., Williams, R.F., Cowan, B.D., Lynch, A., Lerner, S.P. \& Hodgen, G.D. (1981) Pulsatile pituitary gonadotropin secretion during maturation of the dominant follicle in monkeys: estrogen positive feedback enhances the biological activity of LH. Endocrinology 109, 2270-2272.

McNatty, K.P. (1982) Ovarian follicular development from the onset of luteal regression in humans and sheep. In Follicular Maturation and Ovulation, pp. 118. Eds R. Rolland, E.V. van Hall, S. G. Hillier, K. P. McNatty \& J. Schoemaker. Excerpta Medica, Amsterdam.

McNatty, K.P., Hillier, S.G., Van den Boogard, A.M.J., Trimbos-Kemper, T.C.M., Reichert, L.E., Jr \& Van Hall, E.V. (1983) Follicular development during the luteal phase of the human menstrual cycle. J. clin. Endocr. Metab. 56, 1022-1031.

Meites, J., Bruni, J.F., Van Vugt, D.A. \& Smith, A.F. (1979) Relation of endogenous opioid peptides and 
morphine to neuroendocrine functions. Life Sciences 24, 1325-1336.

Midgley, A.R., Jr \& Jaffe, R. (1968) Regulation of human gonadotrophins: IV. Correlation of serum concentrations of follicle stimulating and luteinizing hormones during the menstrual cycle. J. clin. Endocr. Metab. 28, 1699-1703.

Mikhail, G. (1970) Hormone secretion by the human ovaries. Gynecol. Invest. 1, 5-20.

Nilsson, L., Wikland, M. \& Hamberger, L. (1982) Recruitment of an ovulatory follicle in the human following follicle-ectomy and lute-ectomy. Fert. Steril. 37, 30-34.

Ross, G.T., Cargille, C.M., Lipsett, M.B., Radford, P.L., Marshall, J.R., Scott, C.A. \& Rodbard, D. (1970) Pituitary and gonadal hormones during spontaneous and induced ovulatory cycles. Recent Prog. Horm. Res. 26, 1-62.

Scaramuzzi, R.J., Corker, C.S., Young, G. \& Baird, D.T. (1975) Production of antisera to steroid hormones in sheep. In Steroid Immunoassay, pp. 111-122. Eds E. H. D. Cameron, S. G. Hillier \& K. Griffiths. Alpha Omega Alpha Publishing, Cardiff.

Schwartz, N.B. (1974) The role of FSH and LH and of their antibodies on follicle growth and on ovulation. Biol. Reprod. 10, 236-272.
Siegel, S. (1956) Non-Parametric Statistics. McGraw Hill, New York.

Strott, C.A., Cargille, C.M., Ross, G.T. \& Lipsett, M.B. (1970) The short luteal phase. J. clin. Endocr. Metab. 30, 246-251.

Swanston, I.A., McNatty, K.P. \& Baird, D.T. (1977) Concentration of prostaglandin $\mathrm{F}_{2_{\alpha}}$ and steroids in the human corpus luteum. $J$. Endocr. 73, 115-122.

Van Look, P.F.A., Lothian, H., Hunter, W.M., Michie, E.A. \& Baird, D.T. (1977) Hypothalamic-pituitaryovarian function in perimenopausal women. Clin. Endocr. 7, 13-31.

Vaughan-Williams, C.A., McNeilly, A.S. \& Baird, D.T. (1982) Assessment of pituitary secretory capacity in women with hypogonadotrophic hypogonadism using a long-acting synthetic analogue of LHRH. Br. J. Obstet. Gynaec. 89, 738-744.

Wonnacolt, T.H. \& Wonnacolt, R.J. (1972) Introductory Statistics. John Wiley, New York.

Yen, S.S.C., Vandenberg, G., Tsai, C.C. \& Parker, D.C. (1974) Ultradian fluctuations of gonadotropins. In Biorhythms and Human Reproduction, pp. 203-218. Eds M. Ferin, F. Halberg, R. M. Richart \& R. L. Van de Wiele. John Wiley, New York.

Received 5 August 1983 